Research Article

\title{
Knowledge Assessment on Hospital Related Occupational Hazard among Student Nurses of Selected College in Delhi
}

\author{
Ritwik Masih', Neha John', , Jamal Fatima $^{3}$ \\ ${ }^{1}$ MSc Nursing Student, ${ }^{2,3}$ Assistant Professor, Rufaida College of Nursing, Jamia Hamdard, Delhi, India. \\ DOI: https://doi.org/10.24321/2455.9318.202104
}

I $\mathbf{N}$ F $\mathbf{O}$

\section{Corresponding Author:}

Neha John, Rufaida College of Nursing, Jamia Hamdard, Delhi, India.

E-mail Id:

nehajohn1812@gmail.com

Orcid Id:

http://orcid.org/0000-0002-0653-2003

How to cite this article:

Masih R, John N, Fatima J. Knowledge Assessment on Hospital Related Occupational Hazard among Student Nurses of Selected College in Delhi. Int J Nurs Midwif Res. 2021;8(1):18-21.

Date of Submission: 2021-02-23

Date of Acceptance: 2021-03-09

\section{$\begin{array}{llllllll}\mathbf{A} & \mathbf{B} & \mathbf{S} & \mathbf{T} & \mathbf{R} & \mathbf{A} & \mathbf{C} & \mathbf{T}\end{array}$}

Introduction: Nurses encounter numerous hazards on the job ranging from needle stick injuries, allergies, and stress to violence. Though measures can be taken to prevent such hazards still they encounter such events in the hospitals. The main objectives of the study are to assess the knowledge of student nurses on hospital-related occupational hazards and to seek the association between the knowledge of student nurses regarding hospital-related occupational hazards with demographic variables.

Method: The research approach used is quantitative approach and the design is descriptive survey design. The sample included 85 student nurses selected through the total enumeration method. Data were collected through an online structured knowledge questionnaire.

Results: The findings of the study revealed that majority of the students i.e. $59 \%$ had moderate knowledge, $26 \%$ had poor knowledge, and only $15 \%$ had good knowledge regarding hospital-related occupational hazards. There was a significant association of the knowledge related to occupational hazard with age and course of study of the students.

Conclusion: The study concluded that there is a need to improve the knowledge on hospital-related occupational hazards among student nurses and hence an e-booklet was developed and disseminated to improve their knowledge on such hazards.

Keywords: Occupational Hazards, Knowledge, Student Nurses

\section{Introduction}

Globally, healthcare professionals constitute about $12 \%$ of the working population. Hospital is one of the most hazardous occupational environments. Medical professionals encounter various other hazards in addition to the commonly occurring occupational hazards.

Though this is a known fact, still it is neglected by governments and management. Nurses due to long hours of work and their nature of work face ergonomic injuries which are the most prevalent, other than this, they are also prone to blood-borne infections leading to diseases like HIV, and Hepatitis B thus increasing morbidity and death among these workers, further leading to loss of skilled personnel which ultimately compromises the already strained health system. ${ }^{1}$ 
Psychosocial, physical, biological, chemical and ergonomic variables may be grouped as health-related hazards related to health professionals. 29 physical types, 25 chemical types, 24 biological varieties, 10 ergonomic types, and 6 types of psycho-social potential hazards have been identified by "the American National Institute for Occupational Safety and Health (NIOSH). ${ }^{2}$

Nursing students are also exposed to hospital-related hazards during their training. A study on 140 students at a nursing school depicted that almost all the students have low knowledge and awareness related to hospital hazards and safety.

Students had experienced blood and body fluids, and faced problems in getting Personnel Protective Equipment (PPE). Other hazards like back pain, verbal assault, anxiety, fatigue, and irritability were also seen. ${ }^{3}$

Hence the need was felt to investigate the level of knowledge of student nurses related to occupational hazards. Keeping this in mind, the investigators undertook this study.

\section{Aim}

The aim of the study was to assess the knowledge of student nurses regarding hospital-related occupational hazards and to seek association between the knowledge of student nurses regarding these hazards with demographic variables like age, gender, course of study etc.

\section{Method}

The approach selected for conducting this study was quantitative research approach with descriptive survey design. The study was conducted during January-February 2020.

The setting of the study was Rufaida College of Nursing, Jamia Hamdard, Delhi. The study was conducted on nursing students. Total enumeration method was adopted for the selection of 85 student nurses studying in Nursing. Only 4th year BSc Nursing students and GNM 3rd year students of Rufaida College of Nursing were selected. Ethical clearance was taken from the Ethical Committee of Jamia Hamdard and informed consent was taken from students before data collection. A structured knowledge questionnaire was used to assess the knowledge of nursing students regarding hospital-related occupational hazards. Online survey method was used for data collection.

Both descriptive and analytical statistics were used to analyse the data. Frequencies and percentages were used to describe sample characteristics. The knowledge level of student nurses regarding hospital-related occupational hazards was assessed as good, moderate, and poor knowledge and the association of knowledge of student nurses with selected demographic variables was computed through chi-square test.

\section{Result}

Table I.Frequency and Percentage Distribution of Demographic Profile of Sample

\begin{tabular}{|c|c|c|c|}
\hline S. No. & Sample Characteristics & Frequency & Percentage \\
\hline \multirow{4}{*}{1.} & \multicolumn{3}{|l|}{ Age (years) } \\
\hline & $\leq 20$ & 27 & 32 \\
\hline & $21-23$ & 55 & 65 \\
\hline & $24-30$ & 03 & 03 \\
\hline \multirow{4}{*}{2.} & \multicolumn{3}{|l|}{ Gender } \\
\hline & Male & 13 & 15 \\
\hline & Female & 72 & 85 \\
\hline & Other & 00 & 00 \\
\hline \multirow{3}{*}{3.} & \multicolumn{3}{|l|}{ Name of the Course } \\
\hline & GNM & 40 & 47 \\
\hline & BSc Nursing & 45 & 53 \\
\hline \multirow{3}{*}{4.} & \multicolumn{3}{|l|}{ Previous history of hospital hazard } \\
\hline & Yes & 28 & 33 \\
\hline & No & 57 & 67 \\
\hline \multirow{4}{*}{5.} & \multicolumn{3}{|l|}{ Knowledge regarding hospital hazard } \\
\hline & Taught in class & 44 & 52 \\
\hline & Articles and research & 09 & 10 \\
\hline & During clinical experience & 32 & 38 \\
\hline
\end{tabular}


Table 1 depicts the demographic profile of the sample. It shows that majority of the sample was female and the maximum participants belonged to the age group of 21-23 years. Majority had knowledge regarding hospital hazards because it was taught in class.

Figure 1 shows that more than half of the sample i.e.
$59 \%$ had moderate knowledge about hospital-related occupational hazards.

There was a significant association of the knowledge on hospital-related occupational hazards among student nurses with age and course as shown by Fisher exact test at 0.05 level of significance (Table 2).

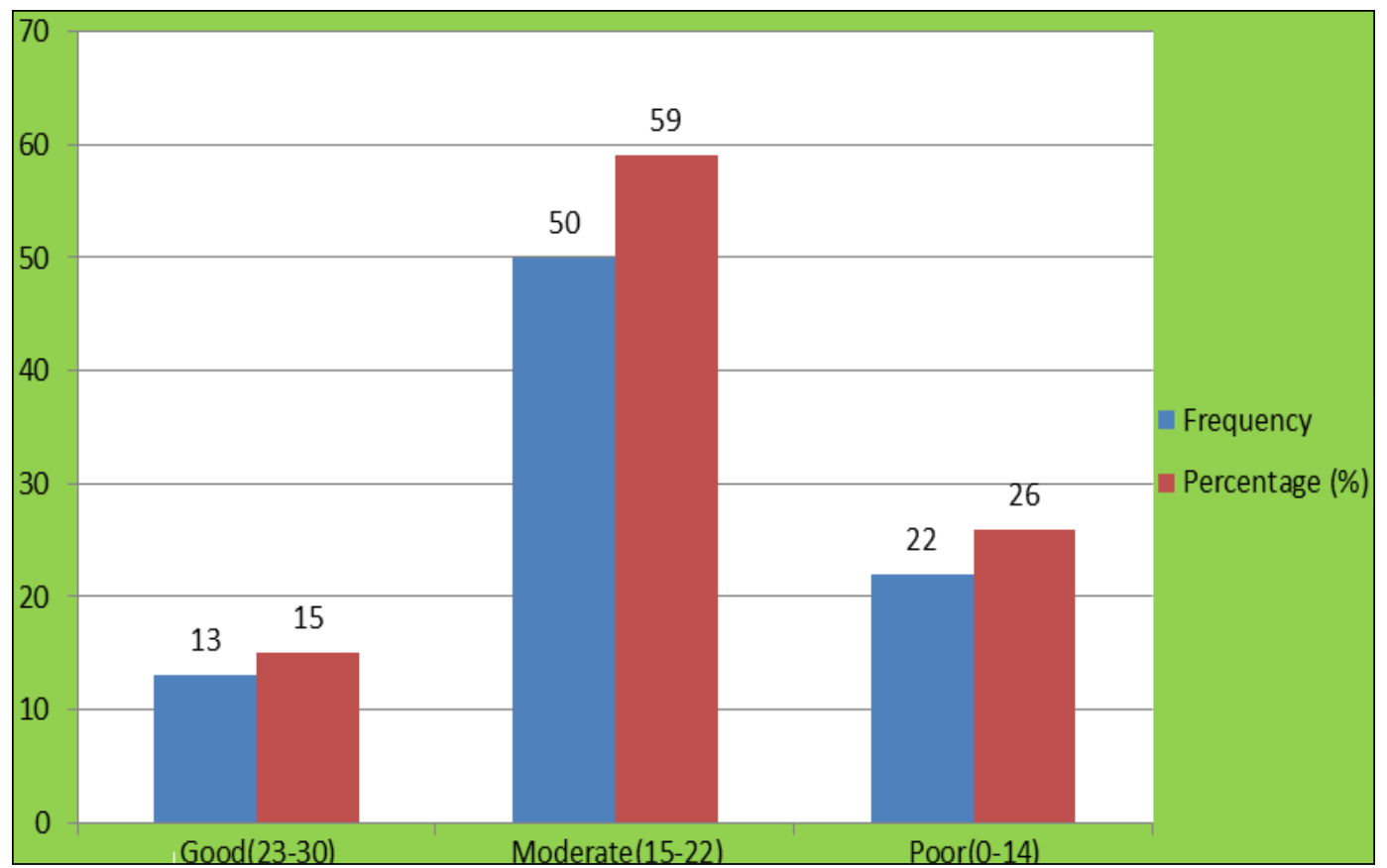

Figure I.Percentage Distribution of Level of Knowledge of Student Nurses regarding Hospital-related Occupational Hazards

Table 2.Association between Knowledge of Student Nurses regarding Hospital-related Occupational Hazards with Selected Demographic Variables

\begin{tabular}{|c|c|c|c|c|c|c|}
\hline \multirow[b]{2}{*}{ Demographic Variables } & \multicolumn{3}{|c|}{ Knowledge Score } & \multirow[b]{2}{*}{ df } & \multirow[b]{2}{*}{$P$ value } & \multirow{2}{*}{$\begin{array}{c}\text { Fisher exact } \\
\text { value }\end{array}$} \\
\hline & $\begin{array}{c}23-30 \\
\text { (Good) }\end{array}$ & $\begin{array}{c}15-22 \\
\text { (Moderate) }\end{array}$ & $\begin{array}{c}\text { 0-14 } \\
\text { (Poor) }\end{array}$ & & & \\
\hline \multicolumn{7}{|l|}{ Age (years) } \\
\hline$\leq 20$ & 0 & 14 & 13 & \multirow{3}{*}{4} & \multirow{3}{*}{$0.0021^{*}$} & \multirow{3}{*}{16.78} \\
\hline $21-23$ & 17 & 33 & 11 & & & \\
\hline $24-30$ & 0 & 3 & 0 & & & \\
\hline \multicolumn{7}{|l|}{ Gender } \\
\hline Male & 2 & 7 & 2 & \multirow{3}{*}{4} & \multirow{3}{*}{0.9825} & \multirow{3}{*}{0.4} \\
\hline Female & 17 & 43 & 20 & & & \\
\hline Others & 0 & 0 & 0 & & & \\
\hline \multicolumn{7}{|l|}{ Name of the course } \\
\hline GNM & 2 & 26 & 12 & \multirow{2}{*}{2} & \multirow{2}{*}{$0.02 *$} & \multirow{2}{*}{7.25} \\
\hline BSc Nursing & 12 & 22 & 11 & & & \\
\hline
\end{tabular}

\footnotetext{
*Significant at 0.05 level
} 


\section{Discussion}

In the present study, the researcher assessed the knowledge of student nurses regarding hospital-related occupational hazards.

A study on dental students' awareness of occupational hazards revealed that there was good knowledge among students regarding occupational hazards. The study findings are inconsistent with the findings of the present study as here only $15 \%$ had good knowledge of hospital-related occupational hazards. ${ }^{4}$

The findings of the present study are consistent with another baseline longitudinal study conducted by Braeckman et al. which aimed to evaluate change in knowledge, attitude and preventive practice of students on occupational hazards at the beginning and end of clinical training. The study revealed that out of 249 students, 147 (56\%) who responded on both instances had inadequate knowledge but after getting into training, their knowledge increased. Both the groups who didn't face any hazard and those who encountered accidental blood contact had similar knowledge of postexposure management. It was concluded that there is a need to improve knowledge and training on the prevention of hospital-related hazards among medical students. ${ }^{5}$

\section{Conclusion}

The study concluded that there is a need to improve the knowledge on hospital-related occupational hazards among student nurses and hence an e-booklet was developed and disseminated to improve their knowledge on such hazards.

\section{Source of Funding: None}

\section{Conflict of Interest: None}

\section{References}

1. Ndejjo R, Musinguzi G, Yu X, Buregyeya E, Musoke D, Wang JS, Halage AA, Whalen C, Bazeyo W, Williams $P$, Ssempebwa J. Occupational health hazards among healthcare workers in Kampala, Uganda. J Environ Public Health. 2015;913741. [PubMed] [Google Scholar]

2. Meydanlıoğlu A. Health and safety of health care workers. J Balikesir Health Sci. 2013;2(3):192-9.

3. Eyi S, Eyi I. Nursing students' occupational health and safety problems in surgical clinical practice. SAGE Open. 2020;10(1):1-21. [Google Scholar]

4. Al-Aslami RA, Elshamy FM, Maamar EM, Shannaq AY, Dallak AE, Alroduni AA. Knowledge and awareness towards occupational hazards and preventive measures among students and dentists in Jazan Dental College, Saudi Arabia. Open Access Maced J Med Sci. 2018 Sep 23;6(9):1722-6. [PubMed] [Google Scholar]

5. Braeckman $L$, Verbrugghe $M$, Janssens $H$, Verpraet $R$, Cobbaut L. Awareness, knowledge, and practices regarding occupational hazards among medical stu- dents: a longitudinal study before and after admission as trainees. J Occup Environ Med. 2017 Apr;59(4):e41-5. [PubMed] [Google Scholar] 